\title{
LA PROBLEMÁTICA DE LA TIERRA EN ESPAÑA DURANTE LA HISTORIA CONTEMPORÁNEA
}

\section{F.M. ESPINO JIMÉNEZ Y M. CALVO-MANZANO JULIÁN (COORDS.)}

\author{
Sevilla, Egregius Ediciones, 2019, 170 páginas
}

ISBN: 978-84-17270-97-1

Las investigaciones que se han venido ocupando del acceso a la tierra en la España Contemporánea cuentan con una larga trayectoria y suman un amplio conjunto de trabajos que nos permite disponer de una detallada aproximación al tema. Un hecho que no impide que todavía se desconozcan cuestiones relevantes o el que otras se presten a ser nuevamente analizadas desde otros enfoques o sumando nuevas fuentes. Este es, precisamente, el espíritu que guía la obra de reciente aparición que aquí nos ocupa. Sus ocho capítulos ofrecen un análisis de algunos problemas del campo español en los siglos XIX y XX, así como de las soluciones que se plantearon para resolverlos.

La puesta en marcha de colonias agrícolas durante el reinado de Isabel II enmarca el contenido de los dos primeros capítulos, elaborados por Adolfo Hamer. La creciente demanda social de reparto de tierras en los primeros momentos del liberalismo isabelino tuvo una respuesta muy tímida por parte de los sucesivos gobiernos que se conformaron en esta etapa. No solo existió una considerable deuda pública que animaba a la clase política a centrarse en los procesos de desamortización, sino que, además, la ausencia de consenso para dar forma a un nuevo marco legislativo impedía afrontar el tema con la amplitud y madurez que requería. Las normas y disposiciones de referencia habían surgido en un contexto absolutista, por lo que solían mostrar fuertes incompatibilidades con la nueva legislación liberal; de ahí la necesidad de dar forma a una nueva ley de colonias agrícolas que diera amparo a las numerosas peticiones que se recibían en los gobiernos civiles provinciales y en las oficinas de algunos ministerios. En el primero de los capítulos mencionados, su autor nos aproxima a los debates que tuvieron lugar en las Cortes españolas, así como en algún grupo de trabajo creado por estas o al que se le pidió informe, acerca de la puesta en marcha de colonias agrícolas en nuestro país durante el referido reinado; centrándose en el análisis y las opiniones que se realizan acerca de la colonización ilustrada de las Nuevas Poblaciones de Sierra Morena y Andalucía. Durante toda la etapa isabelina, estas colonias fueron el gran referente. Sus aciertos y sus errores, así como la posibilidad de que sirvieran de modelo para 
dar forma a una ley estatal, se plasmaron en los discursos y reflexiones de diputados e integrantes de comisiones y grupos de trabajo. Como era de esperar, una combinación de interés personal por defender ciertas ideas y de conocimiento impreciso de esas colonias hizo que fueran consideradas como referente por unos y como experiencia a no repetir por otros. En cualquier caso, la ausencia de voluntad real para dar respuesta efectiva a las necesidades del agro español, en lo que a fundación de colonias agrícolas se refiere, hizo que la primera ley destinada a impulsarlas no se promulgase hasta 1855; una disposición tardía y que pronto demostró su ineficacia. De ahí que el tema de las colonias agrícolas siguiera siendo una preocupación en los años siguientes, volviendo a estar presente el ejemplo de las colonias de Sierra Morena y Andalucía hasta la aprobación una nueva ley en 1868. En el segundo capítulo, por su parte, se centra en el proyecto de ley sobre colonias agrícolas en parajes desiertos, una iniciativa surgida durante la regencia del general Espartero y que a punto estuvo de convertirse en la primera de este tipo que entraba en vigor en el nuevo sistema liberal. Este proyecto no es desconocido para la comunidad científica, que suele mencionarlo como precedente fallido de la ley de 1855 , pero Hamer realiza por primera vez un detallado recorrido sobre su contenido y su inconclusa tramitación parlamentaria.

La Primera República española es el marco temporal en el que se enmarcan los siguientes dos capítulos, de los que es autor Antonio Muñoz. El primero de ellos se centra en el interesante proceso de desamortización, discutido en forma de proyecto, de las Cortes republicanas. A diferencia de iniciativas anteriores, en esta ocasión el cambio en la estructura de la propiedad que al que se aspiraba debía tener como horizonte el posibilitar un régimen de tenencia alodial; se introducía, así, un concepto recurrente en la etapa anterior, y que no era otro que la reivindicación de que la tierra debía ser para el que la trabajaba. Sin embargo, el abrupto final de esta etapa hizo que solo una de las iniciativas legislativas (Ley de agosto de 1873) culminara el trámite parlamentario, por lo que las fincas continuaron vendiéndose según lo dispuesto por Madoz en 1855. En su segundo capítulo, Muñoz nos aproxima a la figura del cordobés Enrique Pérez de Guzmán (1826-1902), marqués de Santa Marta, un destacado político de ideales democráticos y, posteriormente, republicanos que, según su biógrafo (Enrique Vera, 1894) había tratado de impulsar durante la Primera República desde la Dirección General del Patrimonio que fue de la Corona un proyecto para enajenar en lotes las fincas dedicadas a paseos y jardines en los reales sitios. De este modo se pondrían en cultivo y facilitarían la creación de un gran número de nuevos propietarios. Ahora bien, el análisis realizado por Muñoz sugiere que este mérito asociado con Pérez de Guzmán no se ajusta a los verdaderos hechos históricos (pues no aparece mencionado en la documentación 
oficial) y es probable que se corresponda con un ejemplo de bulo orientado a ensalzar la labor y reforzar la figura del marqués de Santa Marta ante los círculos republicanos de fines del siglo XIX.

Marcos Calvo-Manzano, por su parte, es el autor de sendos trabajos que se incluyen a continuación y que nos trasladan a comienzos de la pasada centuria. El establecimiento del que fuera el primer seguro social obligatorio en nuestro país (el Retiro Obrero Obligatorio, 1919) ocupa la primera de sus contribuciones. La ineficaz etapa de seguros voluntarios daba paso a una fórmula que contribuiría a la necesaria pacificación social, especialmente por las convulsiones de la segunda década del siglo. No obstante, su puesta en marcha se enfrentó con no pocas dificultades. El Instituto Nacional de Previsión no pudo publicar un primer Reglamento General hasta 1921, momento en el que los trabajadores agrarios quedaron por vez primera integrados en el Retiro Obrero Obligatorio, e incluso así muchos aspectos quedaron pendientes de futuros estudios y fórmulas a concretar. Por otro lado, en su segundo capítulo amplía la información sobre esta época estudiando las opiniones e informaciones sobre las movilizaciones campesinas incluidas en los ejemplares de El Socialista, órgano de expresión del PSOE, durante el conocido como Trienio Bolchevista o Bolchevique en España. Comprueba Calvo-Manzano un progresivo acercamiento de esta cabecera a los problemas del agro y que los objetivos de las movilizaciones campesinas de este periodo no responden a intereses revolucionarios, sino que encajan mejor en las ya clásicas demandas de una crisis de subsistencias.

El séptimo capítulo tiene como objeto central el análisis de la reforma emprendida por la Generalidad catalana en el sistema enfitéutico aplicado a la propiedad de la tierra en Cataluña en 1934 (Ley de contratos de cultivo), coincidiendo con un momento de pleno poder de la derecha a nivel estatal. Como era de esperar, esta iniciativa vino acompañada de una intensa pugna política y jurídica. Daniel Guerra nos muestra cómo las autoridades catalanas, de corte progresista, trataron de hacer valer sus competencias frente al gobierno central que consideraba que aquellas se había extralimitado. Un enfrentamiento en el que la izquierda, sobre todo el PSOE, opta por sumarse al gobierno catalán argumentando que no apoyarían ninguna medida que implicase un freno a la reforma agraria. La espinosa cuestión requirió que se pronunciase finalmente el Tribunal de Garantías Constitucionales.

Finalmente, en el octavo y último capítulo, Lola Goytia Goyenechea y Nieves Martínez Roldán se aproximan a las transformaciones urbanísticas y territoriales experimentadas en dos zonas de colonización, con predominio del regadío, en el margen septentrional del valle del Guadalquivir, entre Córdoba y Sevilla, a mediados del siglo XX. 
Para alcanzar este objetivo, las autoras hacen uso del Sistema de Información Geográfica, una herramienta que les permite interrelacionar la componente espacial con el temático en estas "Zonas de Interés Nacional” contempladas en el Plan General de Colonización del Instituto Nacional de Colonización. Entre las principales conclusiones alcanzadas destacamos la comprobación de que, aunque hubo una intensa actividad colonizadora en la zona, la incidencia de las expropiaciones fue escasa. Del mismo modo, a pesar de que los nuevos pueblos se situaron muy cercanos a los núcleos de cabecera, se prefirió su configuración autónoma y no reforzar la trama ya existente; una circunstancia que generó no pocos problemas entre los distintos núcleos.

En suma, nos encontramos ante una obra imprescindible para quienes deseen profundizar en nuevos ámbitos y enfoques relacionados con la problemática de la tierra en la España Contemporánea. El rigor y el detalle con el que sus autores abordan las diferentes cuestiones estudiadas facilitarán, sin duda, que futuras investigaciones sobre el tema se vean enriquecidas con sus aportaciones.

Francisco José Pérez-Schmid Fernández

HUM155: Laboratorio de Experimentación Espacial (LABe2) de la Universidad de Jaén 